\title{
Some Like it Hot: Cardioprotective Effect of Curcumin in Chronic Kidney Disease
}

\author{
Editorial to: "Cardioprotection by Curcumin Post-Treatment in Rats with Established \\ Chronic Kidney Disease” by S. Hernandez-Resendiz et al.
}

\author{
Elena N. Dedkova ${ }^{1}$
}

Published online: 15 April 2015

(C) Springer Science+Business Media New York 2015

$\begin{array}{ll}\text { Abbreviations } \\ {\left[\mathrm{Ca}^{2+}\right]_{\mathrm{m}}} & \text { Mitochondrial free calcium concentration } \\ \mathrm{CKD} & \text { Chronic kidney disease } \\ \mathrm{CVD} & \text { Cardiovascular disease } \\ \text { CsA } & \text { Cyclosporin A } \\ \text { mPTP } & \text { Mitochondrial permeability transition pore } \\ \text { ROS } & \text { Reactive oxygen species } \\ \Delta \Psi_{\mathrm{m}} & \text { Mitochondrial membrane potential }\end{array}$

Chronic kidney disease (CKD) is a progressive loss of kidney structure (i.e., proteinuria, abnormal urinary sediment, abnormalities on imaging studies) and function (i.e., glomerular filtration rate (GFR) $<60 \mathrm{~mL} / \mathrm{min}$ per $1.73 \mathrm{~m}^{2}$ ) over a period of 3 months or longer which leads to accumulation of water, waste, and toxic substances in the body that are normally excreted by the kidney [1]. The presence of CKD confers a markedly increased risk of cardiovascular disease, and in fact patients with CKD die primarily from cardiovascular complications rather than from end-stage renal failure $[2,3]$. The kidney plays a central role in electrolyte balance, volume, and blood pressure regulation; all of these parameters have a significant impact on cardiovascular health [4]. If the kidneys fail to work properly, fluid builds up quickly in the lungs and heart leading to hypervolemia. This increases the workload of

Elena N. Dedkova

elena_dedkova@rush.edu

1 Department of Molecular Biophysics and Physiology, Rush University Medical Center, 1750 W. Harrison St, Chicago, IL 60612, USA the heart and could lead to chronic heart failure due to volumeoverload with increased central venous pressure and low systematic arterial pressure [5]. This in turn reduces net renal perfusion pressure, further reducing renal function and stimulating many neurohumoral factors such as the renin-angiotensin-aldosterone system (RAAS), the sympathetic nervous system, including the adrenals, and the arginine-vasopressin system, to maintain renal blood supply [6]. In addition, the metabolic disturbances in CKD accelerate the atherosclerotic process causing vascular calcification and stiffness leading to pressure overload. Histopathological studies indicate that capillary density is reduced in the hypertrophied myocardium, and pronounced interstitial fibrosis is a dominant feature of CKD-associated structural myocardial remodeling [5]. Furthermore, higher rates of arrhythmias and sudden death are observed in CKD due to shifts in electrolyte balance and myocardial substrate.

Therefore, the primary and secondary prevention of future cardiovascular events in CKD patients remains an important clinical goal. There are four types of traditional medicine used in CKD: 1) angiotensin-converting enzyme inhibitors (ACEIs); 2) angiotensin II receptor blockers/antagonists (ARBs); 3) beta-blockers; and 4) statins. Unfortunately, the traditional drugs and therapies currently used for CKD treatment rarely have effects on prevention of cardiovascular complications associated with CKD and have numerous negative side effects emerging the search for alternative strategies to prevent cardiac remodeling in CKD. The study from Cecilia Zazueta's group sought to determine the effect of curcumin in treating heart dysfunction in rats with established chronic kidney disease (CKD) [7]. In their previous study, they reported that curcumin pre-treatment to rats subjected to subtotal nephrectomy, prevented the increase in systolic blood pressure (SBP), reduced renal dysfunction and preserved cardiac 
function [8] suggesting that curcumin also has a potential for treatment of cardiovascular complications during CKD. Curcumin (diferuoylmethane or 1,7-bis (4-hydroxy-3methoxyphenol)-1,6-hepatadiene-3,5-dione) is major component of the spice turmeric, has been used throughout history as a dietary spice in Indian and Chinese cuisine and coloring agent in foods and cosmetics [9]. This extract has been widely used in traditional eastern medicine for the treatment of a variety of disorders including wound healing, rheumatism, diabetic ulcers, anorexia, cough and sinusitis [10]. Modern scientific research has demonstrated anti-inflammatory, antioxidant, anti-carcinogenic, and anti-thrombotic effects of curcumin, however very little is known regarding the effect of curcumin on the cardiovascular diseases especially during CKD $[11,12]$. The current study was performed in $5 / 6 \mathrm{Nx}$ rats subjected to subtotal nephrectomy consisted of surgical removal of the right kidney and selective infarction of approximately two-thirds of the left kidney by ligation of two or three branches of the renal artery [13] and control rats subjected to ventral laparotomy (manipulation of kidney and renal pedicle without destruction of renal tissue). Curcumin administration $(120 \mathrm{mg} / \mathrm{kg} /$ day via oral gavages) was initiated at day $30 \mathrm{after}$ nephrectomy that correlated with expression of the factors indicating the activation of cardiac remodeling pathways (i.e., increased metalloproteinase-2 (MMP-2) levels and increased interventricular and rear wall thickening) and continued the treatment for 30 days in both groups. They found that curcumin post-treatment restored systolic blood pressure, diminished interventricular and rear wall thickening, decreased left ventricular dimension at end-systole and restored ejection fraction in $5 / 6 \mathrm{Nx}$ rats. This restoration in heart function was associated with diminished oxidative stress by curcumin posttreatment. Direct measurements of reactive oxygen species (ROS) with fluorescent probe DCF revealed almost 2-fold increase in ROS generation following subtotal nephrectomy which corresponded with a significant increase in protein oxidation. Curcumin decreased ROS generation, protein oxidation as well as reduced MMP-2 levels and the gelatinolytic activity of metalloproteinases indicating that the antioxidant effect of curcumin correlated with protection against matrix remodeling. Matrix remodeling in nephrectomized rats was also associated with mitochondrial damage as demonstrated by the decreased mitochondrial membrane potential $\left(\Delta \Psi_{\mathrm{m}}\right)$ and inability of mitochondria from $5 / 6 \mathrm{Nx}$ rats to retain calcium $\left(\mathrm{Ca}^{2+}\right)$ in response to application of $100 \mu \mathrm{M}$ of external $\mathrm{Ca}^{2+}$. Both these parameters were rescued by cell treatment with cyclosporin $\mathrm{A}$, which inhibits the mitochondrial permeability transition pore (mPTP), a non-specific mega-channel on the inner mitochondrial membrane, opening of which has been associated with the initiation of cell death. Authors determined that curcumin post-treatment restored $\mathrm{Ca}^{2+}$-retention capacity of mitochondria, preserved $\Delta \Psi_{\mathrm{m}}$, prevented mPTP opening and cell death. These findings also suggest that curcumin can modulate cytosolic $\mathrm{Ca}^{2+}$ concentration in the heart. Indeed it has been shown that curcumin can effectively block $\mathrm{IP}_{3}$ receptors [14] and decrease ATP-induced $\mathrm{Ca}^{2+}$ release from the endoplasmic reticulum in intact HL-60 cells. Increased expression and activity of $\mathrm{IP}_{3}$ receptors in cardiac cells have been associated with the development of chronic atrial fibrillation [15], hyperthrophy [16] and heart failure [17], and therefore it is plausible to speculate that curcumin can prevent detrimental cardiovascular events via modulation of $\mathrm{IP}_{3}$ receptor activity.

Prior studies have demonstrated that matrix remodeling in nephrectomized rats was associated with activation of the canonical Akt and ERK1/2 signaling pathways [18]. Interestingly, neither PI3/Akt/GSK3 nor MEK1/2-ERK1/2 pathways were activated in $5 / 6 \mathrm{Nx}$ rats, although a slight decrease in PI3K phosphorylation was observed in 5/6 Nx rats treated with curcumin. These results could be explained by the fact that $\mathrm{PI} / \mathrm{Akt} / \mathrm{GSK} 3$ and MEK1/2-ERK1/2 pathways are typically associated with the development of the advanced heart failure. In the present study only the early signs of cardiac remodeling were detected which could be associated with the compensated hypertrophy and activation of the cacineurin rather than $\mathrm{PI} 3 / \mathrm{Akt} / \mathrm{GSK} 3$ and MEK1/2-ERK1/2 signaling pathways. The anti-inflammatory effect of curcumin is typically mediated through multiple mechanisms involving inhibition of various transcription factors such as NF- $\mathrm{KB}$ and down-regulation of pro-inflammatory cytokines such as TNF- $\alpha$ and IL- $6^{12}$. In addition, curcumin was previously shown to up-regulate the expression and activity of nuclear factor erythroid 2 (Nrf2) [19], whose downstream proteins were shown to have important functions in protection against oxidative stress [20]. Definitely, more studies are required to warrant this possibility and analyze other cascades involved in heart remodeling during CKD.

To summarize, the elegant study of Hernandez-Resendiz et al. [7] clearly demonstrated that curcumin has potential for treatment of heart disease in patients with established CKD by attenuating oxidative stress-related events as cardiac remodeling, mitochondrial dysfunction and cell death. Spice your food - it could save your heart!

\section{References}

1. Levey AS, Coresh J. Chronic kidney disease. Lancet. 2012;379: $165-80$

2. Selvarajah S, Uiterwaal CS, Haniff J, van der Graaf Y, Visseren FL, Bots ML, et al. Renal impairment and all-cause mortality in cardiovascular disease: effect modification by type 2 diabetes mellitus. Eur J Clin Investig. 2013;43:198-207.

3. Go AS, Chertow GM, Fan D, McCulloch CE, Hsu CY. Chronic kidney disease and the risks of death, cardiovascular events, and hospitalization. N Engl J Med. 2004;351:1296-305. 
4. McCullough PA. Cardiovascular disease in chronic kidney disease from a cardiologist's perspective. Curr Opin Nephrol Hypertens. 2004;13:591-600.

5. Herzog CA, Asinger RW, Berger AK, Charytan DM, Diez J, Hart $\mathrm{RG}$, et al. Cardiovascular disease in chronic kidney disease. A clinical update from Kidney Disease: Improving Global Outcomes (KDIGO). Kidney Int. 2011;80:572-86.

6. Liu PP. Cardiorenal syndrome in heart failure: a cardiologist's perspective. Can J Cardiol. 2008;24(Suppl B):25B-9.

7. Hernandez-Resendiz S, Correa F, Garcia-Nino WR, BuelnaChontal M, Roldan FJ, Ramirez-Camacho I, Delgado-Toral C, Carbo R, Pedraza-Chaverri J, Tapia E, Zazueta C. Cardioprotection by curcumin post-treatment in rats with established chronic kidney disease. Cardiovasc Drugs Ther. 2015;29: this issue.

8. Correa F, Buelna-Chontal M, Hernández-Reséndiz S, García-Niño WR, Roldán FJ, Soto V, et al. Curcumin maintains cardiac and mitochondrial function in chronic kidney disease. Free Radic Biol Med. 2013;61:119-29.

9. Gupta SC, Prasad S, Kim JH, Patchva S, Webb LJ, Priyadarsini IK, et al. Multitargeting by curcumin as revealed by molecular interaction studies. Nat Prod Rep. 2011;28:1937-55.

10. Akbik D, Ghadiri M, Chrzanowski W, Rohanizadeh R. Curcumin as a wound healing agent. Life Sci. 2014;116:1-7.

11. Goel A, Kunnumakkara AB, Aggarwal BB. Curcumin as "Curecumin": from kitchen to clinic. Biochem Pharmacol. 2008;75:787-809.

12. Prasad S, Gupta SC, Tyagi AK, Aggarwal BB. Curcumin, a component of golden spice: from bedside to bench and back. Biotechnol Adv. 2014;32:1053-64.
13. Tapia E, Soto V, Ortiz-Vega KM, Zarco-Marquez G, Molina-Jijon E, Cristobal-Garcia M, et al. Curcumin induces Nrf2 nuclear translocation and prevents glomerular hypertension, hyperfiltration, oxidant stress, and the decrease in antioxidant enzymes in 5/6 nephrectomized rats. Oxid Med Cell Longev. 2012;2012:269039.

14. Dyer JL, Khan SZ, Bilmen JG, Hawtin SR, Wheatley M, Javed MU, et al. Curcumin: a new cell-permeant inhibitor of the inositol 1,4,5-trisphosphate receptor. Cell Calcium. 2002;31:45-52.

15. Yamda J, Ohkusa T, Nao T, Ueyama T, Yano M, Kobayashi S, et al. Up-regulation of inositol 1,4,5 trisphosphate receptor expression in atrial tissue in patients with chronic atrial fibrillation. J Am Coll Cardiol. 2001;37:1111-9.

16. Arantes LA, Aguiar CJ, Amaya MJ, Figueiro NC, Andrade LM, Rocha-Resende C, et al. Nuclear inositol 1,4,5-trisphosphate is a necessary and conserved signal for the induction of both pathological and physiological cardiomyocyte hypertrophy. J Mol Cell Cardiol. 2012;53:475-86.

17. Yoo SH. Chromogranins and inositol 1,4,5-trisphosphate-dependent $\mathrm{Ca}(2+)$-signaling in cardiomyopathy and heart failure. Curr Med Chem. 2012;19:4068-73.

18. Ghosh SS, Salloum FN, Abbate A, Krieg R, Sica DA, Gehr TW, et al. Curcumin prevents cardiac remodeling secondary to chronic renal failure through deactivation of hypertrophic signaling in rats. Am J Physiol Heart Circ Physiol. 2010;299:H975-84.

19. Zeng C, Zhong P, Zhao Y, Kanchana K, Zhang Y, Khan ZA, et al. Curcumin protects hearts from FFA-induced injury by activating $\mathrm{Nrf2}$ and inactivating NF-kappaB both in vitro and in vivo. J Mol Cell Cardiol. 2015;79:1-12.

20. Ma Q. Role of nrf2 in oxidative stress and toxicity. Ann Rev Pharmacol Toxicol. 2013;53:401-26. 